\title{
Development of Metarhizium anisopliae and Beauveria bassiana formulations for control of malaria mosquito larvae
}

\author{
Tullu Bukhari*, Willem Takken, Constantianus JM Koenraadt
}

\begin{abstract}
Background: The entomopathogenic fungi Metarhizium anisopliae and Beauveria bassiana have demonstrated effectiveness against anopheline larvae in the laboratory. However, utilising these fungi for the control of anopheline larvae under field conditions, relies on development of effective means of application as well as reducing their sensitivity to UV radiation, high temperatures and the inevitable contact with water. This study was conducted to develop formulations that facilitate the application of Metarhizium anisopliae and Beauveria bassiana spores for the control of anopheline larvae, and also improve their persistence under field conditions.

Methods: Laboratory bioassays were conducted to test the ability of aqueous ( $0.1 \%$ Tween 80 ), dry (organic and inorganic) and oil (mineral and synthetic) formulations to facilitate the spread of fungal spores over the water surface and improve the efficacy of formulated spores against anopheline larvae as well as improve spore survival after application. Field bioassays were then carried out to test the efficacy of the most promising formulation under field conditions in western Kenya.
\end{abstract}

Results: When formulated in a synthetic oil (ShellSol T), fungal spores of both Metarhizium anisopliae and Beauveria bassiana were easy to mix and apply to the water surface. This formulation was more effective against anopheline larvae than $0.1 \%$ Tween 80 , dry powders or mineral oil formulations. ShellSol T also improved the persistence of fungal spores after application to the water. Under field conditions in Kenya, the percentage pupation of An. gambiae was significantly reduced by $39-50 \%$ by the ShellSol T-formulated Metarhizium anisopliae and Beauveria bassiana spores as compared to the effects of the application of unformulated spores.

Conclusions: ShellSol T is an effective carrier for fungal spores when targeting anopheline larvae under both laboratory and field conditions. Entomopathogenic fungi formulated with a suitable carrier are a promising tool for control of larval populations of malaria mosquitoes. Additional studies are required to identify the best delivery method (where, when and how) to make use of the entomopathogenic potential of these fungi against anopheline larvae.

\section{Background}

Recently, theoretical and experimental studies have shown the potential of entomopathogenic fungi as next generation agents for the control of malaria mosquitoes [1-5] However, most of this work has focused on targeting adult mosquitoes. Larval control has a convincing history of malaria eradication and recent studies have also shown this approach to be highly effective [6-11]. It

\footnotetext{
* Correspondence: tullu.bukhari@wur.nl

* Correspondence: tullu.bukhari@wur.nl Netherlands
}

(c) 2011 Bukhari et al; licensee BioMed Central Ltd. This is an Open Access article distributed under the terms of the Creative Commons Attribution License (http://creativecommons.org/licenses/by/2.0), which permits unrestricted use, distribution, and reproduction in any medium, provided the original work is properly cited.

is, therefore, worthwhile to investigate the ability of entomopathogenic fungi to control mosquito larvae and the feasibility of their operational use.

Our previous work showed the efficacy of Metarhizium anisopliae (ICIPE-30) and Beauveria bassiana (IMI- 391510) spores in infecting and killing larvae of Anopheles stephensi and An. gambiae under laboratory conditions [12]. Other isolates of $M$. anisopliae and $B$. bassiana have also been shown to affect culicine and anopheline larvae [13-17]. The main infection sites were the feeding and respiratory apparatus [16]. Most of these studies had been carried out in the laboratory and 
proved the application of dry fungal spores to be more effective than the application of formulated spores $[13,14,18]$. Applying dry spores in the field, however, has certain limitations. Fungal spores are hydrophobic by nature so when applied in an aquatic environment, they clump together, reducing the area that is effectively covered. As a result, massive amounts of fungal spores are required. Contact with water also disrupts the infection process. Attachment of spores to the host is an important step of the infection process. The outer layer of spores has highly organised surface proteins known as rodlets, which are mainly responsible for attachment to the host [19]. For successful infection, germination should follow spore attachment to the host. When dry fungal spores are applied to an aquatic habitat, typical for mosquito larvae, the nutrients in the water are usually sufficient to stimulate germination in the spores following water intake $[20,21]$. Once a spore germinates, the outer layer is ruptured reducing the chance of attachment to the host. Water contact, thus, reduces the pathogenicity of the floating spores. In addition, dry unformulated fungal spores are more exposed to UV radiation and high temperatures, which are known to negatively affect spore persistence and germination rate $[22,23]$.

In addition to strain selection and genetic modification, formulation can have a considerable impact on improving the efficacy of biopesticides. An ideal formulation aids the handling and application of the biopesticides, as well as increases its efficacy by improving contact with the host and protecting the active agent from environmental factors [24]. Considering the surface feeding behaviour of anopheline larvae, any formulation intended to infect them should spread the fungal spores over the water surface $[25,26]$. The larvae are then most likely to come in contact with spores. The spores should spread uniformly, providing equal coverage, over the entire treated area. In addition, spores should be prevented from germinating before host attachment, and at least to some extent be protected from environmental factors. In this context we developed and tested dry (organic and inorganic), oil (mineral and synthetic) and water-based formulations of $M$. anisopliae and B. bassiana for their efficacy against anopheline larvae.

The objectives of this study were to (a) develop formulations suitable for the positioning (water surface or bottom) and uniform spread of $M$. anisopliae and $B$. bassiana spores, (b) assess the efficacy of selected spore formulations in killing anopheline larvae, (c) assess the selected formulations for their potential to increase spore persistence, and (d) assess the potential of formulations to suppress populations of mosquito larvae in a field situation.

\section{Methods}

\section{Mosquitoes}

Anopheles gambiae s.s. (Suakoko strain, courtesy of Prof. M. Coluzzi, reared in laboratory for 23 years) and $A n$. stephensi (Strain STE 2, MR4 no. 128, origin India, reared in laboratory for 2 years after obtaining the eggs from MR4) were reared separately, but under similar conditions, in climate-controlled rooms at Wageningen University, The Netherlands. The temperature was maintained at $27 \pm 1^{\circ} \mathrm{C}$. Relative humidity was set at 70 $\pm 5 \%$ and the rooms had a 12L:12D photoperiod. Larvae were kept in plastic trays filled with tap water. First instar larvae were fed on Liquifry No. 1 (Interpet Ltd. Surrey, UK) while older instar stages were fed on Tetra$\min ^{\circledR}$ (Tetra, Melle, Germany). The resulting pupae were transferred to holding cages $(30 \times 30 \times 30 \mathrm{~cm})$ in small cups, where they emerged as adults with ad libitum access to $6 \%$ glucose water. The female mosquitoes were blood-fed with the Hemotek membrane feeding system. Human blood (Sanquin ${ }^{\circledR}$, Nijmegen, The Netherlands) was used for this purpose and mosquitoes could feed on it through a Parafilm $M^{\circledR}$ membrane. Eggs were laid on moist filter paper, and were subsequently transferred to the larval trays. For the field bioassays An. gambiae s.s. eggs (Kisumu, strain, reared in laboratory for 8 years) were obtained from the Kenya Medical Research Institute (KEMRI) and reared at the Ahero Multipurpose Development Training Institute (AMDTI), Kenya. Rearing was carried out under local climate conditions (described below) and larvae were fed on Tetramin ${ }^{\circledR}$.

\section{Fungal spores}

Metarhizium anisopliae (ICIPE-30) and Beauveria bassiana (IMI- 391510) spores were obtained from the Department of Bioprocess Engineering, Wageningen University, and stored as dry spores in Falcon ${ }^{\mathrm{TM}}$ tubes at $4^{\circ} \mathrm{C}$. Metarhizium anisopliae spores are olivaceous green, cylindrical and 2.5-3.5 $\mu \mathrm{m}$ long while $B$. bassiana spores are hyaline, spherical or sub-spherical and have a diameter of 2-3 $\mu \mathrm{m}$ [27].

\section{Carrier materials}

Wheat flour, white pepper, WaterSavr (WaterSavr ${ }^{\mathrm{TM}}$, Sodium bicarbonate version, Flexible Solutions International Ltd., Victoria BC, Canada), 0.1\% Tween 80 aqueous solution, Ondina oil 917 (Shell Ondina ${ }^{\circledR}$ Oil 917, Shell, The Netherlands) and ShellSol T (Shellsol T ${ }^{\circledR}$, Shell, The Netherlands) were tested for their potential as carrier of fungal spores. Wheat flour and white pepper served as organic dry carriers. These were tested because anopheline larvae are known to aggregate around and feed on powdered organic materials (wheat flour, alfalfa flour, blood meal and liver powder) even 
when a choice of inorganic materials (chalk, charcoal and kaolin) is also available [28]. One inorganic dry powder, known as WaterSavr, was also tested. WaterSavr consists of fine bicarbonate granules that selfspread over the water surface forming a thin layer which has been shown to reduce evaporation [29]. Its biodegradability, safety and surface-spreading features made it a suitable candidate for inclusion in our tests. Surfactants, such as Tween 80 , can be used to overcome the hydrophobic nature of fungal spores and form a homogeneous aqueous solution. Fungal spores formulated in Tween 80 have been used in bioassays to test the efficacy of fungal spores against mosquito larvae [13,16,30-34]. ShellSol $\mathrm{T}$ is a synthetic isoparaffinic hydrocarbon solvent. Ondina oil 917, slightly denser than ShellSol T, is a highly refined mineral oil. Both ShellSol T and Ondina oil 917 have been successfully used as carrier for fungal spores to target the adult stage of mosquitoes [1,35].

\section{Formulations}

The first selection of carriers suitable for formulating entomopathogenic fungal spores consisted of a test in which the carrier material was evaluated for its ability to spread over the water surface. For this purpose, plastic trays $(25 \times 25 \times 8 \mathrm{~cm})$ were filled with $1 \mathrm{~L}$ of tap water and the carriers applied on the water surface $\left(441 \mathrm{~cm}^{2}\right)$. The least amount of each carrier required to cover the entire surface was recorded. Once that amount was determined, $M$. anisopliae spores $\left(10 \mathrm{mg}, \sim 4.7 \times 10^{8}\right.$ spores) were added to the carriers. The quantity of the carriers was increased to make a consistent suspension or mixture of fungal spores and carriers. The resulting formulations were applied to select the carriers that spread the spores evenly over the water surface evenly. Metarhizium anisopliae spores were used because of their colour (olivaceous green) which made it easy to visualize them whilst spreading.

Efficacy of formulations against Anopheles gambiae larvae The next step consisted of testing selected formulations against An. gambiae larvae in laboratory bioassays. Bioassays were performed under climatic conditions similar to the mosquito rearing. Plastic trays $(25 \times 25 \times$ $8 \mathrm{~cm}$ ) were filled with $1 \mathrm{~L}$ of tap water and allowed to acclimatise overnight. Fifty second-instar larvae were added to each tray. Unformulated or formulated spores were applied to the water surface of each tray. The number of larvae that died or pupated was recorded daily for the next eight days. For each treatment, the carrier alone (in the same quantity as in the formulation) served as the control. In the case of unformulated spores, the control was untreated tap water. The larvae were provided with Tetramin ${ }^{\circledR}$ as food at the rate of 0.2
- $0.3 \mathrm{mg} / \mathrm{larva}$ per day. The experiments were replicated three times.

\section{Pathogenicity of floating unformulated spores over time}

A third experiment was performed to evaluate how the pathogenicity of fungal spores is affected by being in contact with water over a time period of seven days. At the start, 15 plastic trays (same size as above) were each filled with one liter of water. These trays were kept overnight in a climate-controlled room to acclimitise. Metarhizium anisopliae spores were applied to the water surface in five trays (10 $\mathrm{mg}$ per tray). Similarly, 10 $\mathrm{mg}$ of $B$. bassiana spores $\left(\sim 2 \times 10^{9}\right.$ spores $)$ were applied on the water surface in five other trays. The remaining five trays served as the control. After one day, 50 second-instar An. stephensi larvae were added to one of the trays treated with $M$. anisopliae spores, $B$. bassiana spores and one untreated control tray. Similarly larvae were added to remaining trays after either 2 , 3,5 or 7 days after fungal treatment. The mortality and/ or pupation was followed for 9 days. The larvae were fed at the same rate as mentioned before. This experiment was replicated three times.

\section{Effect of formulation on persistence of pathogenicity}

Based on the results of the formulation experiments, the carriers WaterSavr and ShellSol $\mathrm{T}$ were selected and tested further for their ability to increase the persistence of pathogenicity in fungal spores in contact with water. Unformulated and formulated (either with WaterSavr or ShellSol T) M. anisopliae and B. bassiana spores were applied to plastic trays containing $1 \mathrm{~L}$ of acclimatized water. One replicate consisted of 18 trays. A pair of trays was applied with one of the following nine treatments: (1) $10 \mathrm{mg}$ of dry M. anisopliae spores, (2) $10 \mathrm{mg}$ of dry B. bassiana spores, (3) M. anisopliae spores mixed with WaterSavr (10 mg/130 mg), (4) B. bassiana spores mixed with WaterSavr (10 mg/130 mg), (5) M. anisopliae spores mixed with ShellSol T $(10 \mathrm{mg} / 200 \mu \mathrm{l})$, (6) B. bassiana spores mixed with ShellSol T (10 mg/ $200 \mu \mathrm{l})$, (7) WaterSavr (130 mg) only, (8) ShellSol (200 $\mu \mathrm{l})$ only or (9) no treatment. Trays treated with WaterSavr or ShellSol $\mathrm{T}$ without fungal spores and the untreated trays served as control for their respective treatments. Fifty second-instar An. stephensi larvae were added to one tray of each pair on the same day the fungal spores were applied. The same number of larvae was added to the other tray of the pair on the seventh day (based on the results of the previous experiment). The larvae were checked for mortality or pupation for the following 10 days after being added to the trays. The experiment was replicated three times. The trays were topped up with acclimatised tap water, every other day, to compensate for evaporation. 


\section{Field bioassays}

To evaluate the efficacy of unformulated and formulated fungal spores in the field, experiments were carried out in Kenya in May and June, 2010. The experiments were conducted in a restricted part of the Ahero Multipurpose Development and Training Institute (AMDTI) compound. This institute is located $24 \mathrm{~km}$ southeast of Kisumu, in western Kenya ( $\left.0^{\circ} 10^{\prime} \mathrm{S}, 34^{\circ} 55^{\prime} \mathrm{E}\right)$. Malaria is highly endemic in this region and transmission occurs throughout the year. A mean annual Plasmodium falciparum sporozoite inoculation rates (EIR) of 0.4-17 infective bites per year has been shown by recent studies for this region [36]. The region has an annual mean temperature range of $17^{\circ} \mathrm{C}$ to $32^{\circ} \mathrm{C}$, average annual rainfall of $1,000-1,800 \mathrm{~mm}$ and average relative humidity of $65 \%$ [37].

Bioassays were conducted outdoors in 33 plastic containers $(0.30 \mathrm{~m}$ diameter). The plastic containers had two nylon-screened holes $\left(3 \mathrm{~cm}^{2}\right)$, close to the brim, allowing excess rain water to flow out while retaining the larvae. Dry soil from a rice paddy at the Ahero irrigation scheme ( $4 \mathrm{~km}$ from AMDTI) was softened up by adding water. The softened soil was placed at the bottom of each plastic container to form a $2 \mathrm{~cm}$ thick layer. One $\mathrm{L}$ of tap water was then added to each plastic container. The water level was $3 \mathrm{~cm}$ above soil level and exposed a surface area of $450 \mathrm{~cm}^{2}$. Each plastic container was placed in a larger tub that also had a bottom layer of soil but was filled with water to the top. The larger tubs were employed to prevent ants from accessing the plastic container inside. Forty second-instar $A n$. gambiae s.s. larvae, were added to each container. The large tubs, with the containers inside, were arranged in three rows $0.5 \mathrm{~m}$ apart from each other (Figure 1a).

Dry and ShellSol T formulated spores of both fungal species were tested. ShellSol T was the only formulation that successfully met the criteria investigated in the laboratory studies. Two different concentrations (10 mg spores/200 $\mu \mathrm{l}$ ShellSol T and $20 \mathrm{mg}$ spores/230 $\mu$ l ShellSol T) of both $M$. anisopliae and B. bassiana spores were tested. For the larger amount of spores, $230 \mu \mathrm{l}$ ShellSol T was required to make a consistent suspension. Each treatment was randomly applied to three plastic containers. The 11 treatments consisted of dry M. anisopliae spores (10 mg and $20 \mathrm{mg}$ ), dry B. bassiana spores (10 $\mathrm{mg}$ and $20 \mathrm{mg}$ ), ShellSol $\mathrm{T}$ formulated $M$. anisopliae spores $(10 \mathrm{mg} / 200 \mu \mathrm{l}$ and $20 \mathrm{mg} / 230 \mu \mathrm{l})$, ShellSol T formulated B. bassiana spores $(10 \mathrm{mg} / 200 \mu \mathrm{l}$ and $20 \mathrm{mg} / 230 \mu \mathrm{l})$ and only ShellSol T $(200 \mu \mathrm{l}$ and 230 $\mu \mathrm{l})$ while the one remaining tub was untreated. The ShellSol T $(200 \mu \mathrm{l}$ and $230 \mu \mathrm{l})$ and the untreated container served as control for their respective treatments. The number of larvae that died in the containers could not be recorded because it was difficult to recover them

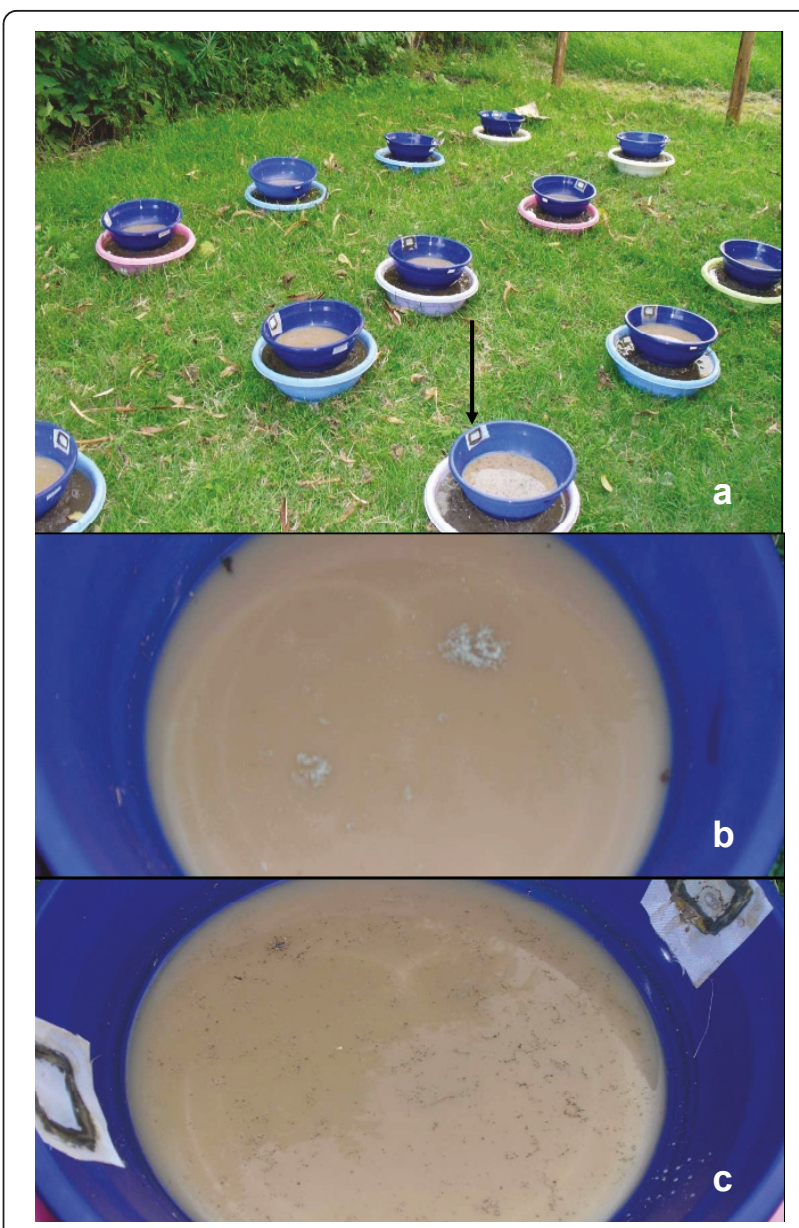

Figure 1 Field bioassays. (a) Forty An. gambiae larvae were placed in plastic containers (with nylon screened holes, indicated by an arrow) with a soil layer $(2 \mathrm{~cm})$ at the bottom and a $3 \mathrm{~cm}$ layer of water. The screened holes were a precautionary measure to retain larvae in the tubs in case of overflow due to heavy rain. The plastic containers were placed in larger tubs, also filled with soil and water, to prevent ants from access to the bioassays. (b) Unformulated (dry) Metarhizium anisopliae (10 mg) spores applied on the water surface. Note the two large clumps just outside the centre of the containers. (c) Shellsol T-formulated Metarhizium anisopliae (10 mg) spores applied on the water surface. Note that spores are spread more evenly over the surface by ShellSol T than dry spores (Figure b).

in the turbid water and/or bottom soil. Therefore, larval survival was assessed as the number of pupae produced. No food was provided to the larvae after being placed in the container. The plastic containers were checked twice daily (for the following 15 days) and pupae were removed with a dipper. To prevent oviposition or emergence of local mosquitoes in the water of larger tubs in which treated plastic containers were placed, Aquatain (a silicone-based oil) was applied to the water surface [38]. Water (0.5 L, kept outdoors in Jerry cans) was added to every plastic container when the water level had been reduced by evaporation to less than $1 \mathrm{~cm}$. 
Meteorological data was obtained from the National Irrigation Board (NIB) research station located approximately $4 \mathrm{~km}$ from the experimental site. Water surface (5 mm top layer) temperature was measured daily at the same time, in each container, with a digital thermometer (GTH 175/Pt, Greisinger electronics, Germany).

\section{Statistical analysis}

Differences in larval survival were analysed using Cox regression [39]. The survival of larvae treated with formulated or unformulated fungal spores were compared with their respective control larvae and the resulting Hazard Ratio (HR) values were used to evaluate differences in mortality rates. The proportional hazard assumption of Cox regression was tested by plotting the cumulative hazard rates against time for the treated and control groups to confirm that the resulting curves did not cross [40].

To test the pathogenicity of fungal spores over time, HR's were computed for larvae exposed to spores floating on water for different time periods. In addition, the arcsine-square root transformed proportions of dead larvae were compared directly, after being corrected for their respective controls using the Abbott's formula, by a one-way ANOVA and LSD post-hoc test of the arcsine transformed mortality proportion [41]. Similarly, the persistence of pathogenicity in formulated and unformulated spores was also compared. The arcsinesquare root transformed proportions of larvae that pupated in the field trial were compared by one-way ANOVA and LSD post-hoc tests. All the analyses were performed using SPSS version 15 software (SPSS Inc. Chicago, IL, USA).

\section{Results}

\section{Formulations}

In the case of both ShellSol T and Ondina oil 917, 100 $\mu \mathrm{l}$ of the oil was required to cover a water surface of $441 \mathrm{~cm}^{2}$. The amounts could not be determined for $0.1 \%$ Tween 80 and wheat flour. Tween 80 solution could not be visualised as it is colourless. The wheat flour formed clumps rather than spreading. White pepper spread across the water surface evenly and $30 \mathrm{mg}$ of it was sufficient to cover the entire surface area. Similarly $130 \mathrm{mg}$ of Watersavr spread and covered the water surface of $441 \mathrm{~cm}^{2}$ (Table 1). After determining these amounts, $10 \mathrm{mg}$ of Metarhizium anisopliae spores was added to each of the carriers. The quantity of ShellSol T and Ondina oil 917 had to be doubled $(200 \mu \mathrm{l})$ to form a homogenous suspension. In case of the $0.1 \%$ Tween 80 solution, $4 \mathrm{ml}$ was required to form a consistent suspension. Wheat flour was not tested further because of clumping. The quantity of white pepper and WaterSavr (30 $\mathrm{mg}$ and $130 \mathrm{mg}$ respectively) required for covering the water surface $\left(441 \mathrm{~cm}^{2}\right)$ was also enough to form a consistent mixture with $10 \mathrm{mg}$ of fungal spores (Table 1). Formulations, apart from the $0.1 \%$ Tween 80 solution which caused the spores to sink, resulted in a fairly uniform spread of fungal spores on the water surface (Table 1 ). Therefore $0.1 \%$ Tween 80 solution was not tested further.

Efficacy of formulations against Anopheles gambiae larvae Bioassays were conducted with unformulated $M$. anisopliae spores (10 $\mathrm{mg}$ ) and M. anisopliae spores formulated in pepper $(10 \mathrm{mg} / 30 \mathrm{mg})$, WaterSavr $(10 \mathrm{mg} / 130 \mathrm{mg})$, ShellSol T $(10 \mathrm{mg} / 200 \mu \mathrm{l}))$ or Ondina oil $917(10 \mathrm{mg} /$ $200 \mu \mathrm{l}$ ) against $A n$. gambiae larvae. Only $2.7 \pm 1.8 \%$ of the larvae treated with unformulated $M$. anisopliae spores pupated while $47.6 \pm 3.9 \%$ pupated in the relevant control. The treated larvae had a nearly two times higher daily risk of mortality as compared to the untreated control larvae $(\mathrm{HR}(95 \% \mathrm{CI})=1.8(1.4-2.4)$, Table 2, Figure 2a). WaterSavr formulation reduced the pupation of the larvae from $67.2 \pm 10.6 \%$ to $1.3 \pm 0.6 \%$, exposing the formulation-treated larvae to nearly three times higher daily risk of mortality as compared to the control (Table 2, Figure 2c). With the ShellSol T formulation $1.3 \pm 0.6 \%$ of the treated larvae pupated while the larvae treated with ShellSol T (without fungal spores) showed 85.4 $\pm 14.5 \%$

Table 1 Carriers tested for their ability to spread spores and the composition of formulations tested

\begin{tabular}{|c|c|c|c|c|}
\hline \multirow[b]{2}{*}{ Carrier } & \multicolumn{2}{|c|}{ Amount required to } & \multirow[b]{2}{*}{ Spore spreading } & \multirow[b]{2}{*}{$\begin{array}{l}\text { Composition of formulations tested in bioassays } \\
\text { (fungal spores/carrier) }\end{array}$} \\
\hline & cover $441 \mathrm{~cm}^{2}$ & $\begin{array}{l}\text { mix } 10 \text { mg of fungal } \\
\text { spores }\end{array}$ & & \\
\hline Wheat flour & - & - & - & - \\
\hline $0.1 \%$ Tween 80 & - & $4 \mathrm{ml}$ & causes spores to sink & - \\
\hline White pepper & $30 \mathrm{mg}$ & $30 \mathrm{mg}$ & on the water surface & $10 \mathrm{mg} / 30 \mathrm{mg}$ \\
\hline WaterSavr & $130 \mathrm{mg}$ & $130 \mathrm{mg}$ & on the water surface & $10 \mathrm{mg} / 130 \mathrm{mg}$ \\
\hline Ondina oil 917 & $100 \mu \mathrm{l}$ & $200 \mu l$ & on the water surface & $10 \mathrm{mg} / 200 \mu \mathrm{l}$ \\
\hline Shellsol T & $100 \mu \mathrm{l}$ & $200 \mu \mathrm{l}$ & on the water surface & $10 \mathrm{mg} / 200 \mu \mathrm{l}$ \\
\hline
\end{tabular}

The amount of each carrier required to cover a water surface area of $441 \mathrm{~cm}^{2}$, the amount required to form a consistent mixture with 10 mg of Metarhizium anisopliae spores, the ability of the carriers to spread the spores over the water surface and the composition of formulations with suitable carriers.

- Not Tested or could not be determined. 
Table 2 Percentage pupation and Hazard ratios of larvae exposed to tested formulations

\begin{tabular}{lcccrr}
\hline & \multicolumn{2}{c}{ Average \% Pupation \pm S.E. } & & \\
\cline { 2 - 3 } Formulation & Control & Treatment & HR(95\%Cl) & p value \\
\hline Unformulated & $47.6 \pm 3.9$ & $2.7 \pm 1.8$ & $1.8(1.4-2.4)$ & $<0.001$ \\
White pepper & 0 & 0 & $0.9(0.7-1.2)$ & 0.959 \\
WaterSavr & $67.2 \pm 10.6$ & $1.3 \pm 0.6$ & $2.7(1.9-3.8)$ & $<0.001$ \\
Ondina oil 917 & 0 & 0 & $1.0(0.8-1.2)$ & 0.806 \\
ShellSol T & $85.4 \pm 14.5$ & $1.3 \pm 0.6$ & $3.7(2.5-5.4)$ & $<0.001$ \\
\hline
\end{tabular}

Average percentage pupation ( \pm S.E.) of An. gambiae larvae exposed to unformulated spores and formulated Metarhizium anisopliae spores $(n=3)$. The carrier in each formulation (White pepper, WaterSavr, Ondina oil 917 or ShellSol T) served as the control. In case of unformulated spores the control was completely untreated. Carrier and Metarhizium anisopliae spores together formed the treatment. Hazard ratio's (HR) indicate the mortality risk in the treatments as compared to their respective controls.

pupation. Larvae exposed to ShellSol T formulated spores of $M$. anisopliae had a mortality risk four times higher compared to larvae treated with ShellSol T only (HR $(95 \% \mathrm{CI})=3.7(2.5-5.4)$, Table 2, Figure 2e). However, with white pepper and Ondina oil there was no significant difference in the mortality of larvae treated with the formulation or the carrier alone, or the formulations and fungal spores together. Both pepper and Ondina oil 917 killed $100 \%$ larvae even without fungal spores (Table 2 , Figure $2 \mathrm{~b}$ and $2 \mathrm{~d}$ ). These two carriers were not tested further as the objective was to develop a formulation that enhances the spreading and efficacy of the fungal spores to infect and kill larvae.

\section{Pathogenicity of floating unformulated spores over time} The pathogenicity of dry $M$. anisopliae and B. bassiana spores was substantially reduced over a period of five days (Figure 3). Anopheles stephensi larvae exposed to $M$. anisopliae spores, applied to water seven days earlier, showed a similar pupation proportion as their control (Table 3). Beauveria bassiana spores lost their effectiveness after being in contact with water for three days. Metarhizium anisopliae spores lost their effectiveness after five days (Table 3). After seven days the control mortality was significantly higher than the mortality of larvae exposed to $M$. anisopliae treatment.

\section{Effect of formulation on persistence of pathogenicity}

Fungal spores formulated with ShellSol T were more persistent compared to the unformulated spores or spores formulated in WaterSavr. Seven days after application only ShellSol $\mathrm{T}$ formulated fungal spores (both $M$. anisopliae and B. bassiana) still caused significant mortality in the An. stephensi larvae (Table 4). Formulation in WaterSavr seemed to reduce the efficacy of fungal spores. When the An. stephensi larvae were exposed to WaterSavr-formulated M. anisopliae and $B$. bassiana spores, on the same day the fungal spores were applied, the corrected proportion larvalmortality was significantly lower as compared to larvae exposed to unformulated M. anisopliae and B. bassiana spores. Larvae exposed to $M$. anisopliae spores formulated with WaterSavr, applied that same day, had a lower mortality risk (HR (95\% CI), 8.9 (4.4-18.1)) than those exposed to the unformulated spores (HR (95\% CI), 44.6 (10.9-181.7)). There was no significant difference in the corrected proportion mortality of larvae exposed to unformulated and WaterSavr-formulated M. anisopliae spores, seven days after their application on water (Figure 4). Similar results were observed for B. bassiana spores. There was no significant difference between the corrected larval-mortality proportion due to unformulated and WaterSavr formulated B. bassiana spores, applied on water seven days before exposing the larvae. Also, the proportion larval mortality caused by WaterSavr-formulated B. bassiana spores was significantly lower than with ShellSol T-formulated B. bassiana spores (Figure 4).

\section{Field bioassays}

During the experimental period (15 days), the mean minimum and maximum temperatures were $15.7^{\circ} \mathrm{C}$ and $30.9^{\circ} \mathrm{C}$, respectively, with a mean relative humidity of $54 \%$ and total rainfall of $19.4 \mathrm{~mm}$. Water surface temperature ranged from $21^{\circ} \mathrm{C}$ to $38.8^{\circ} \mathrm{C}$. Similar to the laboratory observations, unformulated spores clumped together on the water surface (Figure 1b) while ShellSol T-formulated fungal spores were uniformly spread (Figure 1c).

The efficacy of unformulated fungal spores was found to be low under field conditions as compared to laboratory conditions. At dose rates of both $10 \mathrm{mg}$ and $20 \mathrm{mg}$, the same ( $\mathrm{p}>0.05$ ) level of pupation was observed in the $A n$. gambiae larvae treated with unformulated $M$. anisopliae and B. bassiana spores as in the untreated An. gambiae larvae (Figure 5). As observed in the laboratory bioassays, ShellSol $\mathrm{T}$ on its own had no harmful effect on larval development and pupation. A similar proportion ( $\mathrm{p}>0.05$ ) of larvae pupated in the containers treated with ShellSol T $(200 \mu \mathrm{l}$ and $230 \mu \mathrm{l})$ and the untreated containers (Figure 5).

The percentage pupation observed in An. gambiae larvae treated with ShellSol T-formulated $M$. anisopliae spores was 43\% (low dose, $10 \mathrm{mg}$ ) and 49\% (high dose, $20 \mathrm{mg}$ ) lower than that of the corresponding unformulated treatments. However for the lower dose $(10 \mathrm{mg})$ the proportion of larvae that pupated was not significantly different ( $p=0.08$, Figure 5).

The percentage pupation observed in An. gambiae larvae treated with ShellSol T-formulated $B$. bassiana 


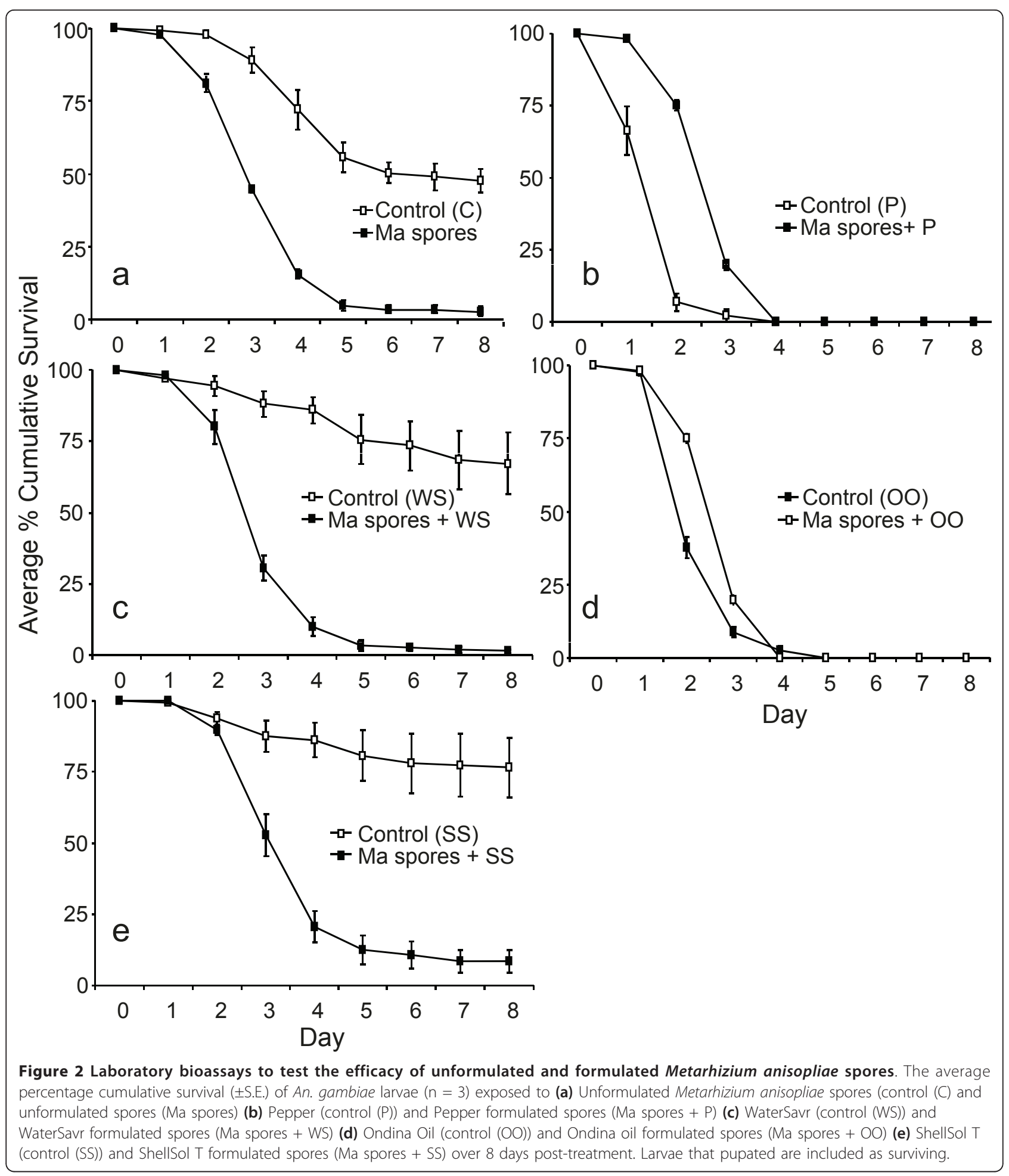

spores was 39\% (low dose, $10 \mathrm{mg}$ ) and 50\% (high dose, $20 \mathrm{mg}$ ) lower than that in the corresponding unformulated treatments. At both lower and higher dose the proportion of larvae that pupated was significantly different $(\mathrm{p}<0.05$, Figure 5).

\section{Discussion}

The results of this study show how certain formulations can improve the ability of entomopathogenic fungus spores to spread over a water surface as well as increase their persistence. The results also show that better 


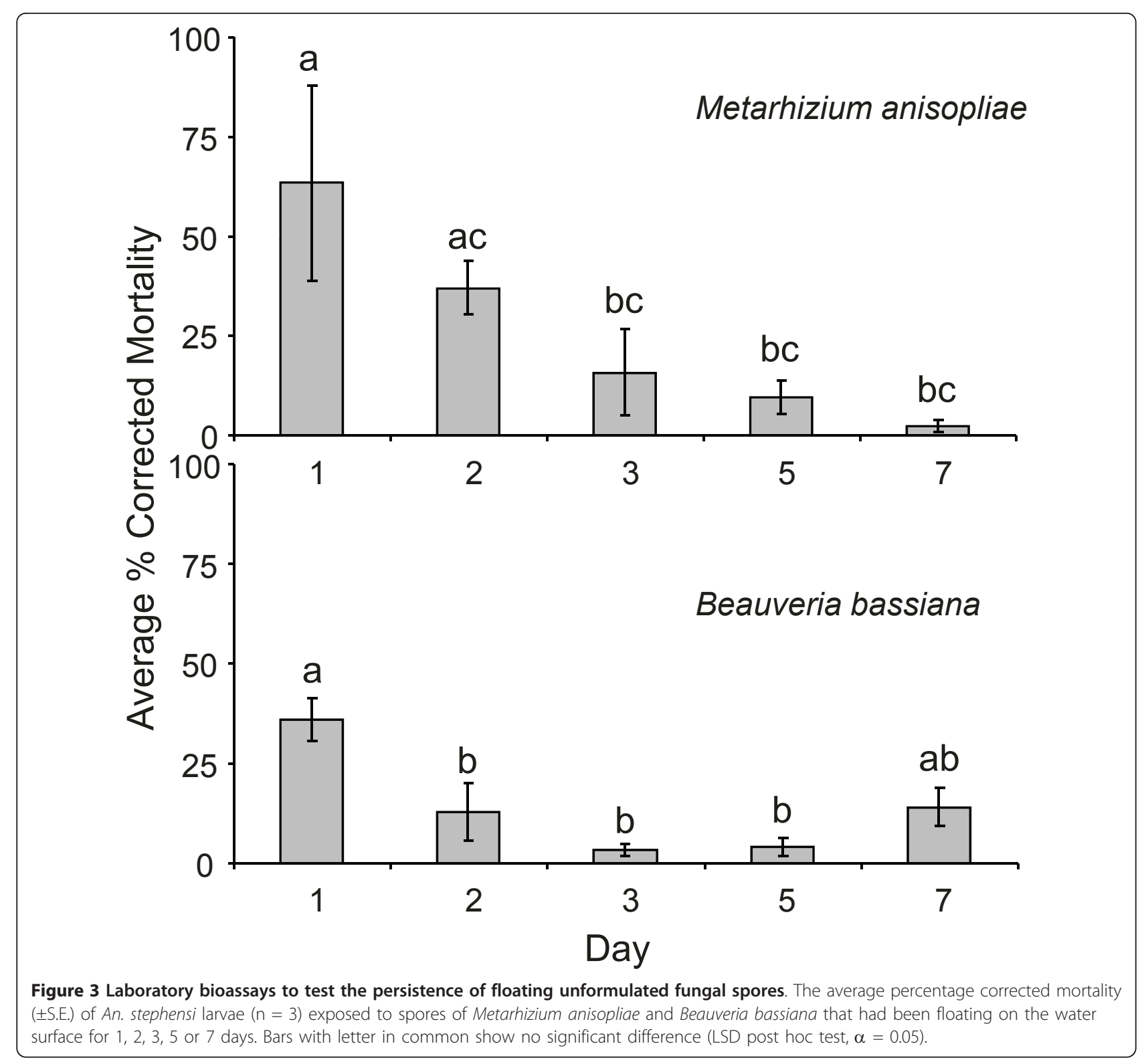

Table 3 Percentage pupation and Hazard ratio's of larvae exposed to unformulated floating fungal spores

\begin{tabular}{|c|c|c|c|c|c|c|c|}
\hline \multirow{3}{*}{$\frac{\text { Treatment }}{\text { Day } 1}$} & \multicolumn{3}{|c|}{ Average \% Pupation (S.E.) } & \multicolumn{4}{|c|}{$\mathrm{HR}(95 \% \mathrm{Cl}) \mathrm{p}$ value } \\
\hline & \multirow{2}{*}{$\begin{array}{c}\text { Control } \\
82.2 \pm 13.5\end{array}$} & \multirow{2}{*}{$\begin{array}{c}\text { Metarhizium anisopliae } \\
36.1 \pm 22.2\end{array}$} & \multirow{2}{*}{$\begin{array}{c}\text { Beauveria bassiana } \\
54.5 \pm 8.4\end{array}$} & \multicolumn{2}{|c|}{ Metarhizium anisopliae } & \multicolumn{2}{|c|}{ Beauveria bassiana } \\
\hline & & & & $5.2(3.4-8.0)$ & $<0.001$ & $3.2(2.0-5.0)$ & $<0.001$ \\
\hline Day 2 & $74.6 \pm 10.8$ & $46.7 \pm 4.9$ & $64.5 \pm 5.3$ & $2.5(1.7-3.6)$ & $<0.001$ & $2.0(1.3-3.0)$ & 0.001 \\
\hline Day 3 & $96.0 \pm 2.3$ & $80.7 \pm 8.5$ & $92.8 \pm 3.4$ & $6.6(2.5-17.2)$ & $<0.001$ & $2.1(0.7-6.0)$ & 0.169 \\
\hline Day 5 & $96.7 \pm 1.7$ & $87.4 \pm 2.7$ & $94.0 \pm 3.0$ & $4.4(1.6-11.8)$ & 0.003 & $1.7(0.5-5.0)$ & 0.347 \\
\hline Day 7 & $84.6 \pm 2.6$ & $84.7 \pm 3.3$ & $72.7 \pm 2.9$ & $0.3(0.2-0.6)$ & $<0.001^{\mathrm{a}}$ & $1.1(0.7-1.9)$ & 0.625 \\
\hline
\end{tabular}

Average percentage pupation ( \pm S.E.) in the control and treated An. stephensi larvae exposed to Metarhizium anisopliae and Beauveria bassiana spores floating on the water surface for $1,2,3,5$ and 7 days $(n=3)$. The controls consisted of untreated trays filled with water at the same time as the treated trays. Hazard ratio's (HR) indicate the mortality risk of larvae as compared to the controls for both Metarhizium anisopliae and Beauveria bassiana spores.

a. HR lower than 1 represents higher mortality in the control group. 
Table 4 Hazard ratios of larvae exposed to (un) formulated fungal spores, $\mathbf{0}$ and $\mathbf{7}$ days post-application

\begin{tabular}{lclcr}
\hline Fungus & Day & Formulation & HR (95\%Cl) & $\begin{array}{r}\mathbf{p} \\
\text { value }\end{array}$ \\
\hline $\begin{array}{l}\text { Metarhizium } \\
\text { anisopliae }\end{array}$ & 0 & Unformulated & $44.6(10.9-181.7)$ & $<0.001$ \\
& & WaterSavr & $8.9(4.4-18.1)$ & $<0.001$ \\
& & ShellSol T & $140.1(18.4-$ & $<0.001$ \\
& 7 & Unformulated & $1.0(0.5-2.0)$ & 0.816 \\
& & WaterSavr & $1.1(0.7-1.8)$ & 0.477 \\
& & ShellSol T & $1.5(1.0-2.2)$ & 0.030 \\
Beauveria bassiana & 0 & Unformulated & $36.1(8.9-146.8)$ & $<0.001$ \\
& & WaterSavr & $10.5(4.7-23.5)$ & $<0.001$ \\
& & ShellSol T & $137.9(18.0-$ & $<0.001$ \\
& & Unformulated & $0.9(0.4-1.7)$ & 0.716 \\
& 7 & WaterSavr & $1.5(0.1-2.3)$ & 0.091 \\
& & ShellSol T & $1.9(1.3-2.9)$ & 0.001 \\
\hline
\end{tabular}

Hazard ratio's (HR) indicate the mortality risk of An. stephensi larvae exposed to unformulated, WaterSavr-formulated and ShellSol T-formulated

Metarhizium anisopliae and Beauveria bassiana spores, 0 and 7 days after application $(n=3)$.

spreading and persistence leads to an enhanced efficacy of fungal spores. The study also demonstrates that both $M$. anisopliae and B. bassiana caused a high impact on the survival of An. gambiae s.s. larvae under field conditions, when formulated in Shellsol T.

Anopheles stephensi and An. gambiae larvae were found to be equally susceptible to unformulated $M$. anisopliae and B. bassiana spores [12]. This suggests that these fungi are likely to also affect other anopheline vector species.

Formulating fungal spores with Tween 80 and wheat flour was found to be unsuitable. Spores formulated with Tween 80 did not spread over the water surface, the primary feeding site of anopheline larvae, but sunk to the bottom $[25,28]$. Surfactants are known to impair attachment of the spore to the host so even if the spores were spread on the water surface they would not have been effective against anopheline larvae $[20,42]$. Wheat flour, although due to its organic nature could have served as a bait, did not spread the fungal spores over the water surface [28]. The wheat flour clumped together and sunk.

Powdered pepper and Ondina oil caused 100\% mortality in anopheline larvae even without the fungal spores. Extracts of fruits of the Piperaceae family have been shown to be toxic for Aedes aegypti L. larvae [43], but the exact toxicity mechanism remains unclear. Although fungal spores were effectively spread with white pepper, pepper was considered an unsuitable carrier due to its own toxic effect on the anopheline larvae. Ondina oil, in the amount tested $(200 \mu \mathrm{l})$, formed an oily layer over the water surface causing the larvae to suffocate. As compared to ShellSol T, Ondina oil is denser and evaporates less. This may explain the difference in the mortality observed with Ondina oil and ShellSol T controls. The amount of Ondina oil tested could not be reduced as, in that case, it was not possible to make a homogeneous suspension with the fungal spores.

Dry unformulated M. anisopliae and B. bassiana spores lost their pathogenicity five days after being applied to the water surface as the survival of larvae exposed to the fungal spores five days after application was similar to that of the controls. Similar results were shown in a study by Alves et al. (2002), where M. anisopliae caused no mortality in Cx. quinquefasciatus Say larvae introduced four days after the spores were applied [13]. This is in contrast to Pereira et al. (2009), who found $M$. anisopliae spores to cause $50 \%$ mortality in Ae. aegypti larvae exposed to fungal spores that were applied ten days previously [34]. The studies mentioned here were carried out in controlled climate conditions $\left(25-27^{\circ} \mathrm{C}\right)$ in the laboratory. In field conditions the spores are more likely to lose their pathogenicity in less time due to exposure to hight temperatures and UVradiations. This may explain why unformulated fungal spores did not cause any significant reduction in pupation in the field bioassays, where the water surface temperatures were measured to be as high as $38.8^{\circ} \mathrm{C}$. The measured (water surface) temperatures agree with those reported by Paaijmans et al. (2008) for similar sized water-bodies and are known to exhibit high daily fluctuations [44].

When the larvae were exposed to fungal spores on the same day as the spores were applied, unformulated spores and spores formulated in WaterSavr or Shellsol $\mathrm{T}$ caused larval mortality over the next few days. However, only fungal spores formulated in ShellSol T caused significantly higher mortality in larvae introduced seven days after the fungal spores had been applied. Fungal spores formulated in ShellSol T remained pathogenic possibly because ShellSol $\mathrm{T}$ prevented spores from absorbing the amount of moisture required to stimulate germination $[21,31]$. ShellSol $\mathrm{T}$ was also considered a good carrier of fungal spores in other studies [31,45]. WaterSavr, on the other hand, did not protect fungal spores.

ShellSol T was the only formulation that we tested in the field as the laboratory results showed high persistence of pathogenicity in the fungal spores formulated only with this product. Unformulated $M$. anisopliae and $B$. bassiana did not suppress the larval population effectively in the field. In contrast to the situation in the laboratory, the spores were exposed to sunlight, rain and fluctuating temperatures in the field which might 


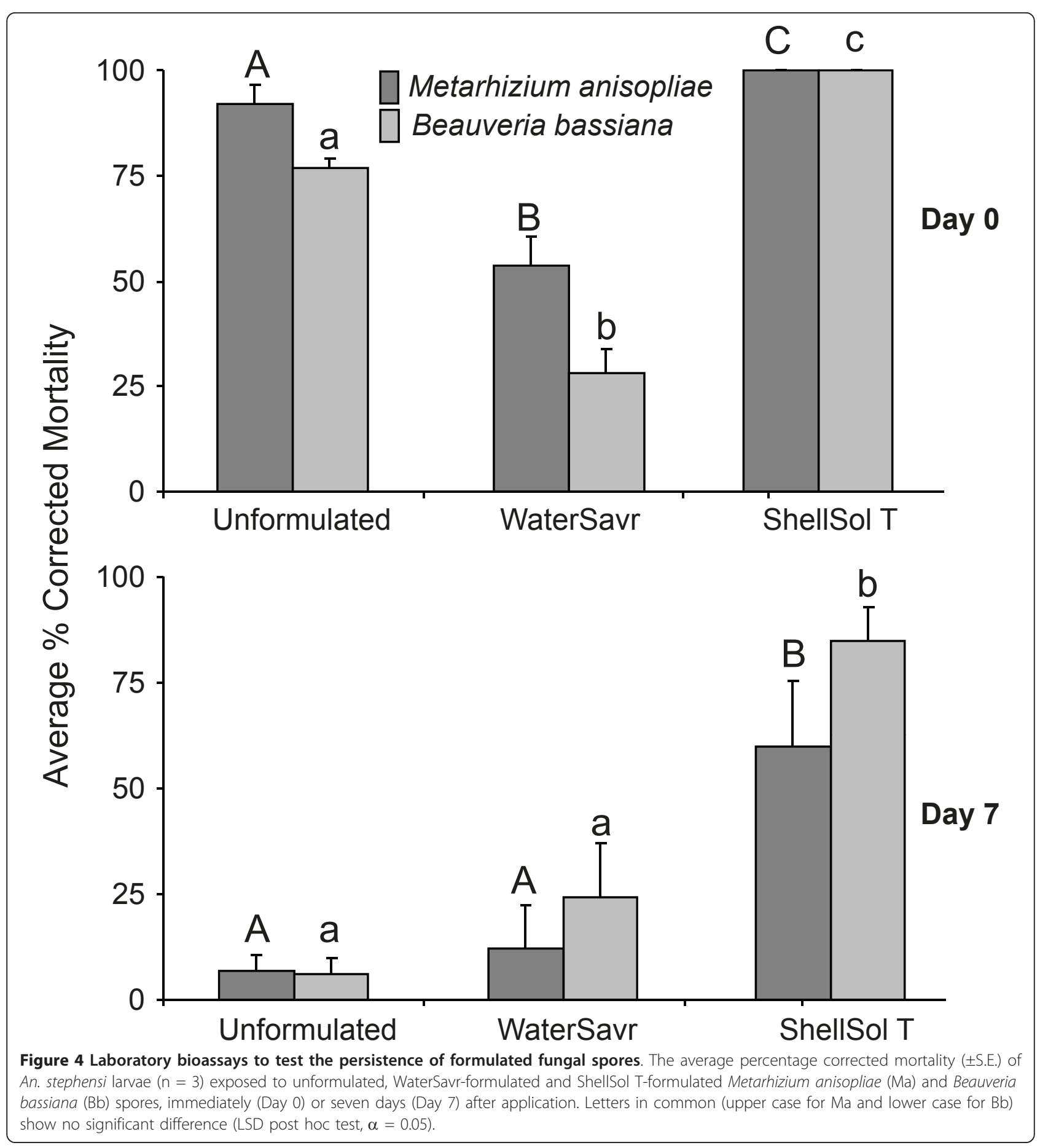

have reduced spore survival. By contrast, only 10-20\% of the larvae treated with spores formulated in ShellSol T, developed into pupae. Both M. anisopliae and B. bassiana spores were found to be equally effective when formulated in ShellSol T. Oil formulations are known to improve spore survival, improve fungal efficacy against insects and reduce spore sensitivity to UV radiation $[31,45]$.
In the field residual effect of formulated spores could not be tested after a certain number of days because the plastic containers began to harbour Culex larvae and thus had to be drained. The presence of Culex larvae is an indication that ovipositing female Culex mosquitoes were not repelled by the fungus treatment. It is disadvantageous for a larval control agent to have an oviposition-repellent effect because in that case ovipositing 


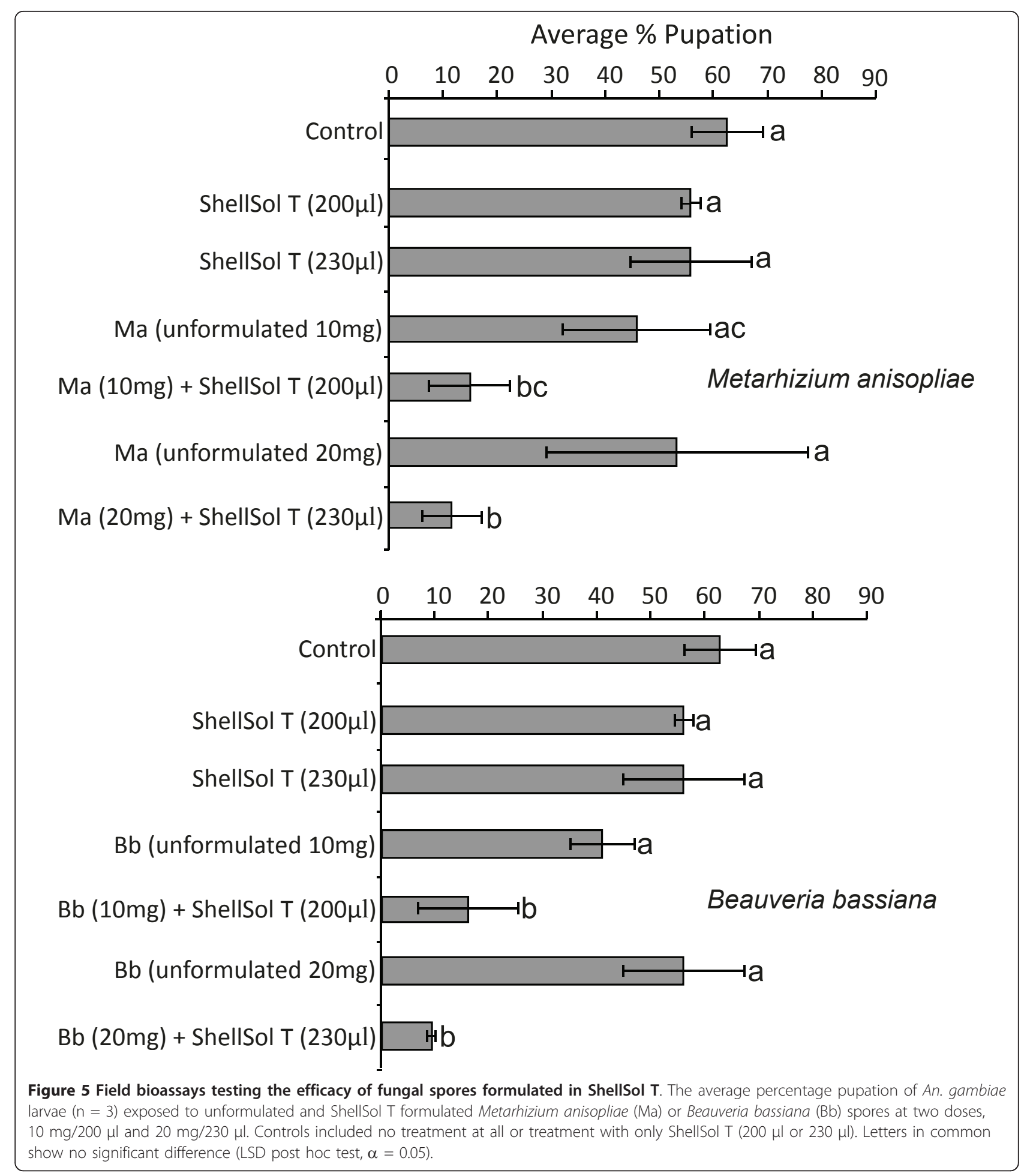

mosquito females are forced to seek and deposit their eggs at alternative untreated sites. This means that the control agent only targets the existing larval population and needs to be reapplied after the site has been inhabited again. Studies specifically designed to establish the response of ovipositing anopheline female mosquitoes to fungal spores and the residual effect of fungal spore treatment are required for a better understanding. Oilformulated $M$. anisopliae spores have been shown to have an increased ovicidal activity in case of Ae. aegypti 
eggs [46]. This might be an added advantage if anopheline eggs are also affected by $M$. anisopliae spores similar to the Ae. aegypti eggs.

Pathogenicity of control agents in the field is generally lower than that in the laboratory settings [47]. In the field bioassays, therefore, a higher dose $\left(20 \mathrm{mg} / 450 \mathrm{~cm}^{2}\right)$ of fungal spores was also tested together with the dose tested in the laboratory $\left(10 \mathrm{mg} / 441 \mathrm{~cm}^{2}\right)$. The laboratory dose, however, showed similar efficacy in the field by reducing pupation similar to the higher dose. Therefore doses lower than used in the current study should be evaluated to establish the lowest effective amount of fungal spores required to treat a certain area.

ShellSol $\mathrm{T}$ was a candidate carrier that not only facilitated the application of spores but also improved their efficacy by providing maximum chance for contact (spreading the spores on the water surface) with the larvae and increasing spore persistence. The fungal spores readily suspend in ShellSol $\mathrm{T}$ with a slight agitation. This is advantageous as the spores can be conveniently mixed in ShellSol T, on the spot, which means that during transport and storage only the bio-active agent would have to be kept at low temperatures rather than the whole mixture. This can reduce the cooling space requirement as ShellSol $\mathrm{T}$ itself is a stable product and has no particular storage demands. It has been shown that the percentage germination of dry spores is generally higher than that of oil-formulated spores when stored at the same temperature for the same number of days [[23]; unpublished data]. The fungal spores Metarhizium flavoviride had a germination rate of $80 \%$ when stored at $30^{\circ} \mathrm{C}$ for 90 days as compared to $90 \%$ when stored dry under similar environmental conditions [23]. In this context, it seems more efficient to store fungal spores separately and only mix them with the oil-component shortly before application.

The results of this study show the necessity of a good formulation for fungal spores when these are to be utilised in the field. The efficacy of unformulated (dry) spores was so low in the field situation that their application, as such, is not justified. While ShellSol T-formulated spores were highly effective in killing anopheline larvae in the field an important point to consider is the potential increased risk to the non-target organisms due to their improved persistence and/or undesirable properties of the solvent [33,48-50]. ShellSol T has a low toxicity effect on fish, aquatic invertebrates and microorganisms at concentration higher than $1 \mathrm{~g} /$ liter [51]. Considering the volume of ShellSol $\mathrm{T}$ that we tested (200-230 $\mu$ l on $1 \mathrm{~L}$ of water), the concentration of ShellSol $\mathrm{T}$ was $0.15 \mathrm{~g} / \mathrm{L}$ which is nearly seven times lower than the lowest lethal concentration. ShellSol T evaporates and therefore is less likely to remain in the aquatic habitats. Detailed safety studies, however, are necessary to have a better understanding of any adverse effect ShellSol T might have on the environment and non-target organisms, at the required doses.

Besides formulation, it is very important to identify the best delivery method (where, when and how) to fully utilize the entomopathogenic potential of $M$. anisopliae and B. bassiana spores. Frequency of re-application has to be determined based on the residual effect of formulated spores in the field. The feasibility of applying formulated spores at artificial breeding sites, baited to attract ovipositing females, is also worth testing [52]. A good delivery system will reduce the chances of non-target organisms coming into contact with fungal spores.

\section{Conclusions}

From a number of candidate products tested for the formulation of entomopathogenic fungi, ShellSol T emerged as a promising carrier of fungal spores when targeting anopheline larvae. Spores of B. bassiana and $M$. anisopliae formulated in ShellSol T had an increased efficacy against larvae of An. gambiae s.s. as compared to unformulated spores and were also more persistent under field conditions in Kenya. Other oils with physical properties similar to ShellSol T may also serve as good carriers. Together with a sound delivery system, these formulated fungi can be utilised in the field, providing additional tools for biological control of malaria vectors.

\section{Acknowledgements}

We thank MR4 for providing An. stephensi eggs and Léon Westerd, André Gidding and Frans van Aggelen for rearing the An. gambiae mosquitoes. Frank van Breukelen and Mgeni Jumbe are acknowledged for providing Metarhizium and Beauveria spores.

We are grateful to Vince Pascarelli for shipping free samples of WaterSavr. In Kenya, we are thankful to Dr Andrew Githeko for supplying An. gambiae eggs, Joel K. Tanui (Research officer, NIB) for access to the meteorological data and Fred Kisanya (Principal, AMDTI) for allowing us to conduct experiments in the institute premises. We appreciate Daniel Ogwang's assistance during the field tests. Tullu Bukhari is funded by HEC, Pakistan, through NUFFIC (The Netherlands). Financial support for the field study was received from the UBS Optimus Foundation, Switzerland and the Adessium Foundation, The Netherlands.

\section{Authors' contributions}

TB designed the study, carried out the experimental work, performed the statistical analysis and drafted the manuscript. CJMK helped with the study design, statistical analyses, and drafting the manuscript. WT provided scientific guidance in interpretation of the findings and drafting the manuscript. All authors read and approved the final manuscript.

\section{Competing interests}

The authors declare that they have no competing interests.

Received: 25 November 2010 Accepted: 22 February 2011 Published: 22 February 2011

\section{References}

1. Farenhorst M, Knols BGJ, Thomas MB, Howard AFV, Takken W, Rowland M, $N^{\prime}$ Guessan R: Synergy in efficacy of fungal entomopathogens and 
permethrin against west African insecticide-resistant Anopheles gambiae mosquitoes. PLOS ONE 5:e12081.

2. Hancock PA: Combining fungal biopesticides and insecticide-treated bednets to enhance malaria control. PLoS Computational Biology 2009, 5 e1000525.

3. Hancock PA, Thomas MB, Godfray HCJ: An age-structured model to evaluate the potential of novel malaria-control interventions: A case study of fungal biopesticide sprays. Proceedings of the Royal Society $B$ : Biological Sciences 2009, 276:71-80.

4. Knols BG, Bukhari T, Farenhorst M: Editorial: Entomopathogenic fungi as the next-generation control agents against malaria mosquitoes. Future Microbiology 5:339-341.

5. Scholte EJ, Ng'habi K, Kihonda J, Takken W, Paaijmans K, Abdulla S, Killeen GF, Knols BGJ: An entomopathogenic fungus for control of adult African malaria mosquitoes. Science 2005, 308:1641-1642.

6. Fillinger U, Ndenga B, Githeko A, Lindsay SW: Integrated malaria vector control with microbial larvicides and insecticide-treated nets in western Kenya: A controlled trial. Bulletin of the World Health Organization 2009, 87:655-665.

7. Killeen GF, Fillinger U, Kiche I, Gouagna LC, Knols BGJ: Eradication of Anopheles gambiae from Brazil: lessons for malaria control in Africa. Lancet Infect Dis 2002, 2:618-627.

8. Killeen GF, Fillinger U, Knols BGJ: Advantages of larval control for African malaria vectors: Low mobility and behavioural responsiveness of immature mosquito stages allow high effective coverage. Malar J 2002, 1:8.

9. Soper FL: Paris green in the eradication of Anopheles gambiae: Brazil, 1940; Egypt, 1945. Mosquito news 1966, 26:470-476.

10. Utzinger J, Tozan Y, Singer BH: Efficacy and cost-effectiveness of environmental management for malaria control. Trop Med Int Health 2001, 6:677-687.

11. Takken W, Snellen WB, Verhave JP, Knols BGJ, Atmosoedjono S: Environmental measures for malaria control in Indonesia - an historical review on species sanitation. Wageningen Agricultural University Papers 1990, 90-7.

12. Bukhari T, Middelman A, Koenraadt CJM, Takken W, Knols BGJ: Factors affecting fungus-induced larval mortality in Anopheles gambiae and Anopheles stephensi. Malaria Journal 2010, 9:22.

13. Alves SB, Alves LFA, Lopes RB, Pereira RM, Vieira SA: Potential of some Metarhizium anisopliae isolates for control of Culex quinquefasciatus (Dipt., Culicidae). Journal of Applied Entomology-Zeitschrift Fur Angewandte Entomologie 2002, 126:504-509.

14. Clark TB, Kellen WR, Fukuda T, Lindegren JE: Field and laboratory studies on the pathogenicity of the fungus Beauveria bassiana to three genera of mosquitoes. Journal of Invertebrate Pathology 1968, 11:1-7.

15. Daoust RA, Ward MG, Roberts DW: Effect of formulation on the virulence of Metarhizium anisopliae conidia against mosquito larvae. Journal of Invertebrate Pathology 1982, 40:228-236.

16. Miranpuri GS, Khachatourians GG: Infection sites of the entomopathogenic fungus Beauveria bassiana in the larvae of the mosquito Aedes aegypti. Entomologia Experimentalis et Applicata 1991, 59:19-27.

17. Sandhu SS, Rajak RC, Sharma M: Bioactivity of Beauveria bassiana and Metarhizium anisopliae as pathogens of Culex tritaeniorhynchus and Aedes aegypti: effect of instar, dosages and time. Indian J Microbiol 1993, 33:191-194.

18. Lacey CM, Lacey LA, Roberts DR: Route of invasion and histopathology of Metarhizium anisopliae in Culex quinquefasciatus. Journal of Invertebrate Pathology 1988, 52:108-118.

19. Boucias DG, Pendland JC, Latge JP: Non specific factors involved in attachement of entomopathogenic Deuteromycetes to host insect cuticle. Applied and Environmental Microbiology 1988, 54:1795-1805.

20. Hegedus DD, Khachatourians GG: The impact of biotechnology on hyphomycetous fungal insect biocontrol agents. Biotechnology Advances 1995, 13:455-490.

21. Burges HD: Formulation of mycoinsecticides. In Formulation of microbial biopesticides: Beneficial microorganisms, nematodes and seed treatments. Edited by: Burges HD. Kluwer, Dordrecht; 1998:131-185.

22. Moore D, Bridge PD, Higgins PM, Bateman RP, Prior C: Ultra-violet radiation damage to Metarhizium flavoviride conidia and the protection given by vegetable and mineral oils and chemical sunscreens. Annals of Applied Biology 1993, 122:605-616.
23. Morley-Davies J, Moore D, Prior C: Screening of Metarhizium and Beauveria spp. conidia with exposure to simulated sunlight and a range of temperatures. Mycological Research 1996, 100:31-38.

24. Goettel MS, Eilenberg J, Glare T, Lawrence IG, Kostas I, Sarjeet SG: Entomopathogenic Fungi and their Role in Regulation of Insect Populations. Comprehensive Molecular Insect Science Amsterdam: Elsevier; 2005, 361-406.

25. Merritt RW, Dadd RH, Walker ED: Feeding behavior, natural food, and nutritional relationships of larval mosquitoes. Annual Review of Entomology 1992, 37:349-376.

26. Ramoska WA, Watts S, Watts HA: Effects of sand formulated Metarhizium anisopliae spores on larvae of three mosquito species. Mosquito News 1981, 41:725-728.

27. de Hoog GS, Guarro J, Gené J, Figueras MJ: Atlas of Clinical Fungi. 2 edition. Utrecht: Centraalbureau voor Schimmelcultures; 2000.

28. Aly C, Mulla MS: Orientation and ingestion rates of larval Anopheles albimanus in response to floating particles. Entomologia Experimentalis et Applicata 1986, 42:83-90.

29. Gosling RD, Drakeley CJ, Chandramohan D: Effective malaria control: better burden estimates needed. The Lancet 371:724-724.

30. Ezzati-Tabrizi R, Talaei-Hassanloui R, Pourian HR: Effect of formulating of Beauveria bassiana conidia on their viability and pathogenicity to the onion thrips, Thrips tabaci lind. (Thysanoptera: Thripidae). Journal of Plant Protection Research 2009, 49:97-104.

31. Inyang EN, McCartney HA, Oyejola B, Ibrahim L, Pye BJ, Archer SA, Butt TM: Effect of formulation, application and rain on the persistence of the entomogenous fungus Metarhizium anisopliae on oilseed rape. Mycological Research 2000, 104:653-661.

32. Meyling NV, Pell JK: Detection and avoidance of an entomopathogenic fungus by a generalist insect predator. Ecological Entomology 2006, 31:162-171.

33. Milner RJ, Lim RP, Hunter DM: Risks to the aquatic ecosystem from the application of Metarhizium anisopliae for locust control in Australia. Pest Management Science 2002, 58:718-723.

34. Pereira CR, de Paula AR, Gomes SA, Pedra PCO, Samuels RI: The potential of Metarhizium anisopliae and Beauveria bassiana isolates for the control of Aedes aegypti (Diptera: Culicidae) larvae. Biocontrol Science and Technology 2009, 19:881-886.

35. Farenhorst M, Farina D, Scholte EJ, Takken W, Hunt RH, Coetzee M, Knols BGJ: African water storage pots for the delivery of the entomopathogenic fungus Metarhizium anisopliae to the malaria vectors Anopheles gambiae s.s. and Anopheles funestus. American Journal of Tropical Medicine and Hygiene 2008, 78:910-916.

36. Ndenga B, Githeko A, Omukunda E, Munyekenye G, Atieli H, Wamai P, Mbogo C, Minakawa N, Zhou G, Yan G: Population dynamics of malaria vectors in western Kenya highlands. Journal of Medical Entomology 2006, 43:200-206.

37. Atieli H, Menya D, Githeko A, Scott T: House design modifications reduce indoor resting malaria vector densities in rice irrigation scheme area in western Kenya. Malaria Journal 2009, 8:108.

38. Bukhari T, Knols BGJ: Efficacy of Aquatain ${ }^{\mathrm{TM}}$, a monomolecular surface film, against the malaria vectors Anopheles stephensi and An. gambiae s. s. in the laboratory. Am J Trop Med Hyg 2009, 80:758-763.

39. Cox DR: Regression models and life tables. J Royal Statist Soc 1972, B:187-220.

40. Haccou $P$, Hemerik $L$ : The influence of larval dispersal in the cinnabar moth (Tyria jacobaeae) on predation by the red wood ant (Formica polyctena): an analysis based on the proportional hazards model. J Anim Ecol 1985, 54:755-769.

41. Abbott WS: A method for computing the effectiveness of an insecticide. J Econ Entomol 1925, 18:265-267.

42. Luz C, Batagin I: Potential of oil-based formulations of Beauveria bassiana to control Triatoma infestans. Mycopathologia 2005, 160:51-62.

43. Yang YC, Lee SG, Lee HK, Kim MK, Lee SH, Lee HS: A piperidine amide extracted from Piper longum L. fruit shows activity against Aedes aegypti mosquito larvae. Journal of Agricultural and Food Chemistry 2002, 50:3765-3767.

44. Paaijmans KP, Jacobs AFG, Takken W, Heusinkveld BG, Githeko AK, Dicke M, Holtslag AAM: Observations and model estimates of diurnal water temperature dynamics in mosquito breeding sites in western Kenya. Hydrological Processes 2008, 22:4789-4801. 
45. Hong TD, Edgington S, Ellis RH, De Muro MA, Moore D: Saturated salt solutions for humidity control and the survival of dry powder and oil formulations of Beauveria bassiana conidia. Journal of Invertebrate Pathology 2005, 89:136-143.

46. Albernaz DAS, Tai MHH, Luz C: Enhanced ovicidal activity of an oil formulation of the fungus Metarhizium anisopliae on the mosquito Aedes aegypti. Medical and Veterinary Entomology 2009, 23:141-147.

47. Becker N, Rettich F: Protocol for the introduction of new Bacillus thurigiensis isrealensis products into the routine mosquito control program in Germany. Journal of the American Mosquito Control Association 1994, 10:527-533.

48. Genthner FJ, Chancy CA, Couch JA, Foss SS, Middaugh DP, George SE, Warren MA, Bantle JA: Toxicity and Pathogenicity Testing of the Insect Pest Control Fungus Metarhizium anisopliae. Arch Environ Contam Toxicol 1998, 35:317-324.

49. Genthner FJ, Foss SS, Fisher WS: Testing of the insect pest-control fungus Beauveria bassiana In grass shrimp Palaemonetes pugio. Dis Aquat Org 1994, 20:49-57.

50. Genthner FJ, Middaugh DP: Non-target testing of an insect control fungus - Effects of Metarhizium anisopliae on developing embryos of the inland silverside fish Menidia beryllina. Dis Aquat Org 1995, 22:163-171.

51. ShellSol T (MSDS). [http://www.ccl.shell.com/MSDS/DownloadRtt? downloadUrl=http://sww.chemicals.shell.com/GSAPEHS/MSDS/ 000000000879_GB_EN.pdf].

52. Sharma KR, Seenivasagan T, Rao AN, Ganesan K, Agrawal OP, Prakash S: Mediation of oviposition responses in the malaria mosquito Anopheles stephensi Liston by certain fatty acid esters. Parasitology Research 2009, 104:281-286.

doi:10.1186/1756-3305-4-23

Cite this article as: Bukhari et al.: Development of Metarhizium anisopliae and Beauveria bassiana formulations for control of malaria mosquito larvae. Parasites \& Vectors 2011 4:23.

\section{Submit your next manuscript to BioMed Central and take full advantage of:}

- Convenient online submission

- Thorough peer review

- No space constraints or color figure charges

- Immediate publication on acceptance

- Inclusion in PubMed, CAS, Scopus and Google Scholar

- Research which is freely available for redistribution

Submit your manuscript at www.biomedcentral.com/submit 